\title{
A NOTE ON SOME CLASSES OF REAL SEQUENCES
}

\author{
L. LEINDLER
}

Abstract. It is shown that the class of real sequences defined by $\breve{Z}$. Tomovski recently is identical with the Fomin's class, furthermore one new class of sequences is defined and compared with some known classes of sequences.

\section{Mathematics subject classification (2000): 26D15, $42 \mathrm{~A} 05$.} sequences.

Key words and phrases: Inequalities, cosine and sine series, embedding relations, quasi-monotone

\section{REFERENCES}

[1] R. P. BOAS JR., Integrability theorems for trigonometric transforms, Springer-Verlag, Ergebnisse 38, Berlin, 1967.

[2] G. A. Fomin, A class of trigonometric series, Mat. Zametki 23 (1978), 213-222.

[3] A. N. Kolmogorov, Sur l'ordre de grandeur des coefficients de la série de Fourier-Lebesgue, Bull. Acad. Polon. Sci. (A), Sci. Math. (1923), 83-86.

[4] L. LeINDLER, On the equivalence of classes of Fourier coefficients, Math. Ineq. \& Applications 3 (2000), 45-50.

[5] L. LEINDLER, On the equivalence of classes of numerical sequences, Analysis Math., (submitted).

[6] S. SIDON, Hinreichende Bedingungen für den Fourier-charakter einer trigonomet-rischen Reihe, J. London Math. Soc. 14 (1939), 158-160.

[7] N. Singh AND K. M. Sharma, Integrability of trigonometric series, J. Indian Math. Soc. 49 (1985), 31-38.

[8] Č. V. Stanojević, Classes of $L^{1}$-convergence of Fourier and Fourier-Stieltjes series, Proc. Amer. Math. Soc. 82 (1981), 209-215.

[9] Č. V. StanojeVić And V. B. Stanojević, Generalizations of the Sidon-Telyakovskĭ theorem, Proc. Amer. Math. Soc. 101 (1987), 679-684.

[10] S. A. TELYAKOVSKII, On a sufficient condition of Sidon for integrability of trigonometric series, Mat. Zametki (Russian) 14 (1973), 317-328.

[11] Ž. Tomovski, An application of the Hausdorff-Young inequality, Math. Ineq. \& Applications 1 (1998), $527-532$.

[12] S. Z. A. ZENEI, Integrability of trigonometric series, Tamkang J. Math. 21 (1990), 295-301. 